This item was submitted to Loughborough's Institutional Repository by the author and is made available under the following Creative Commons Licence conditions.

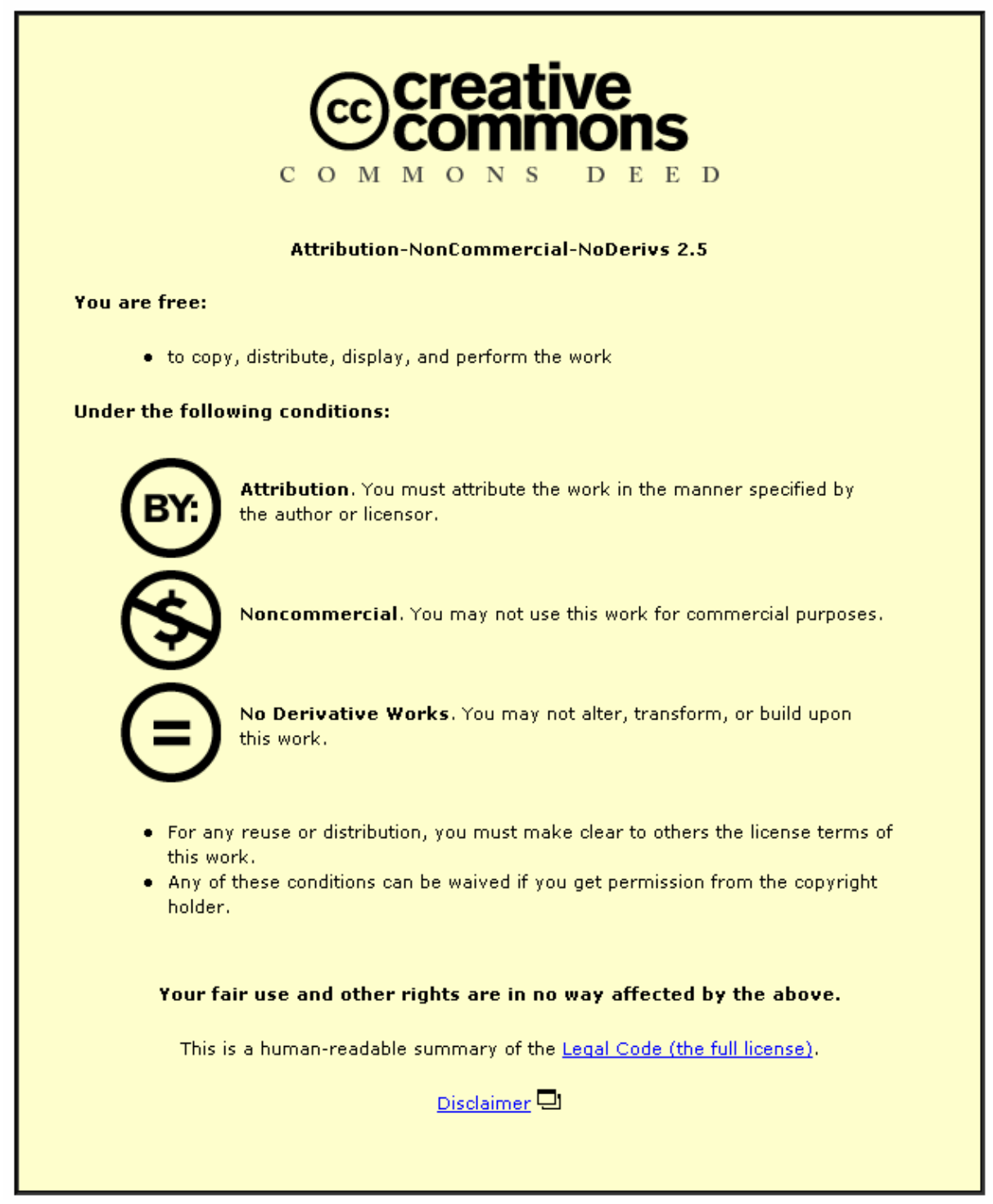

For the full text of this licence, please go to: http://creativecommons.org/licenses/by-nc-nd/2.5/ 

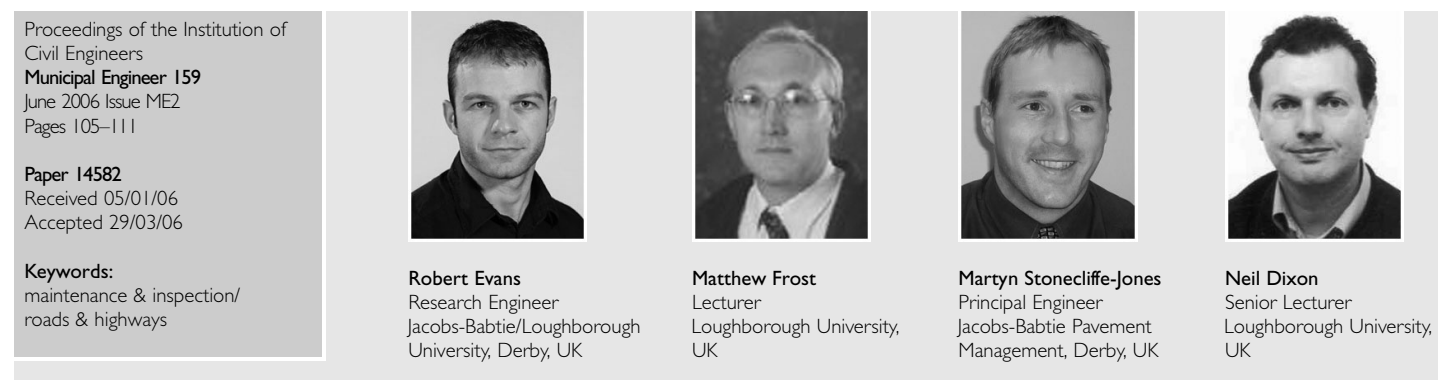

\section{Ground-penetrating radar investigations for urban roads}

\section{R. Evans MSc, FGS, M. Frost PhD, M. Stonecliffe-Jones IEng, AMICE and N. Dixon PhD, FGS}

Although ground-penetrating radar (GPR) technology has existed for many decades, it has only been in the last 15 to 20 years that it has undergone great development and is now a commonly used non-destructive technique to assess layer thicknesses and material condition of trunk road pavement structures. Intrusive investigations provide vital additional information, but are often costly and time-consuming, and have the limitation that only data at discrete points are obtained. The nature of urban sites means that ground conditions are highly variable, and urban pavements are often subject to much maintenance and reconstruction. This can result in roads containing several pavement types or layers of materials of differing age and condition, often overlying discrete buried objects, services or structures. Other site-specific factors can also affect the quality of data obtained. However, it is possible to tailor a GPR survey to optimise data by adjusting the investigation methodology. Using an example of a recent urban pavement investigation, this paper shows how the use of detailed and extensive GPR data collection can be used to target concurrent invasive investigations to optimise the analysis of variable urban pavement structures and hence focus maintenance treatments and methodologies.

\section{INTRODUCTION}

Assessing the condition of urban pavement structures in order to plan maintenance is essential for efficient long-term functioning of the highway network. Optimising the methods used for such assessments will lead to better information on pavement condition. A condition assessment of urban pavements is affected by a number of factors, including the properties of the pavement, the supporting sub-base and sub-grade (natural ground) and the capability of acquiring good information about the entire road area.

Several non-destructive investigative methods that cause minimal damage or disturbance to the pavement structure are available. It is common practice to implement routine investigations of pavement structures and to use the information obtained to target more detailed investigations. Ground-penetrating radar (GPR) is one of the main tools used to provide information of road condition, particularly on the main truck road network. The use of GPR for urban pavement investigation merits special consideration due to the often highly variable and complex nature of the road structure and underlying ground in urban environments. Pavements, sub-bases and the sub-grade often contain different materials and pavement types with different properties in relatively close proximity.

This paper outlines the principles of a GPR investigation in urban roads, the nature of non-trunk urban roads and the specific issues related to their in situ investigation. Optimisation of the on-site methodology for GPR surveys on (non-trunk) urban roads is detailed, using examples of successes and limitations of an actual investigation to illustrate key points. The whole investigation process for the road structure (i.e. pavement, sub-base and sub-grade), from the planning stage through to presentation of information to the end user, is considered.

\section{THE USE OF GPR IN PAVEMENT EVALUATION}

In order to assess the condition of a road, information on its internal structure is required. Core samples or trial pits are often taken and analysed to confirm material type, condition and thickness. While providing vital data, it is costly and time-consuming to take invasive samples. Furthermore, only data from the locations of the cores or trial pits are obtained, and information on sections of road between the samples has to be interpolated. GPR (which transmits and records the passage of electromagnetic waves through media) has become a widespread non-destructive pavement evaluation tool. Intrusive pavement investigations are still required ${ }^{1}$ and are used for calibration of GPR data (this is discussed below), but the amount of intrusive investigation (and the time taken for surveys) can be reduced while the amount of information obtained increased through the use of GPR.

\section{I. Principles of GPR}

GPR systems operate by transmitting a radar pulse from an antenna into the ground and recording the time taken for reflections of this pulse to be returned to the antenna.

The passage of radar waves through a material is dependent on the material type, condition, water content and pore fluid content. These properties affect the dielectric constant of the material, which governs the radar signal speed through the material. When two material layers have contrasting properties, some radar energy is reflected back from the material boundary (Fig. 1). The key to this process is for the materials to have different dielectric constants and, in practice, the majority of in-service road materials (bituminous, cement bound, 


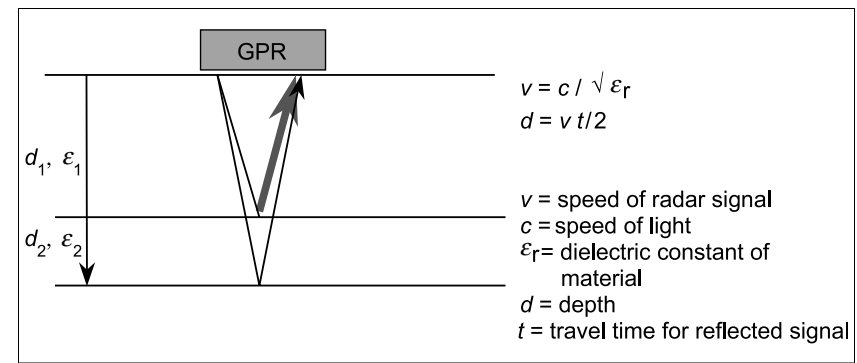

Fig. I. Calculation of radar pulse speed, dielectric constant and depth

unbound aggregates, different soil types, etc.) do have this contrast. The amount of radar energy reflected will depend on the reflection coefficient, which in turn depends on the difference in dielectric properties of the materials.

Ground-penetrating radar operates over a range of signal frequencies, but typically systems that operate between $400 \mathrm{MHz}$ and $2 \mathrm{GHz}$ are used for engineering and 'shallow' investigations. Generally, a higher signal frequency gives a better resolution (i.e. a more precise indication of depth) but a lower penetration (i.e. shallower investigation depth). Conversely, lower frequencies provide less interface resolution, but deeper signal penetration (Fig. 2).

Data from GPR survey lines are typically plotted as a 'pseudo-section' of signal travel time (which may be converted to depth) against chainage, with the amplitude of the reflected signal plotted in colour or greyscale. Fig. 3 shows greyscale plots, with white and black indicating a strong signal reflection (i.e. a material interface), from which the layer interface can be determined.

\subsection{Development of GPR}

Ground-penetrating radar is an accepted method for ground investigations of all kinds, and the reader is directed to the literature $^{2-4}$ for useful overviews of the technology and use of GPR in sub-surface evaluation. Developments in the use of radar in pavements, including technological advances in the design of
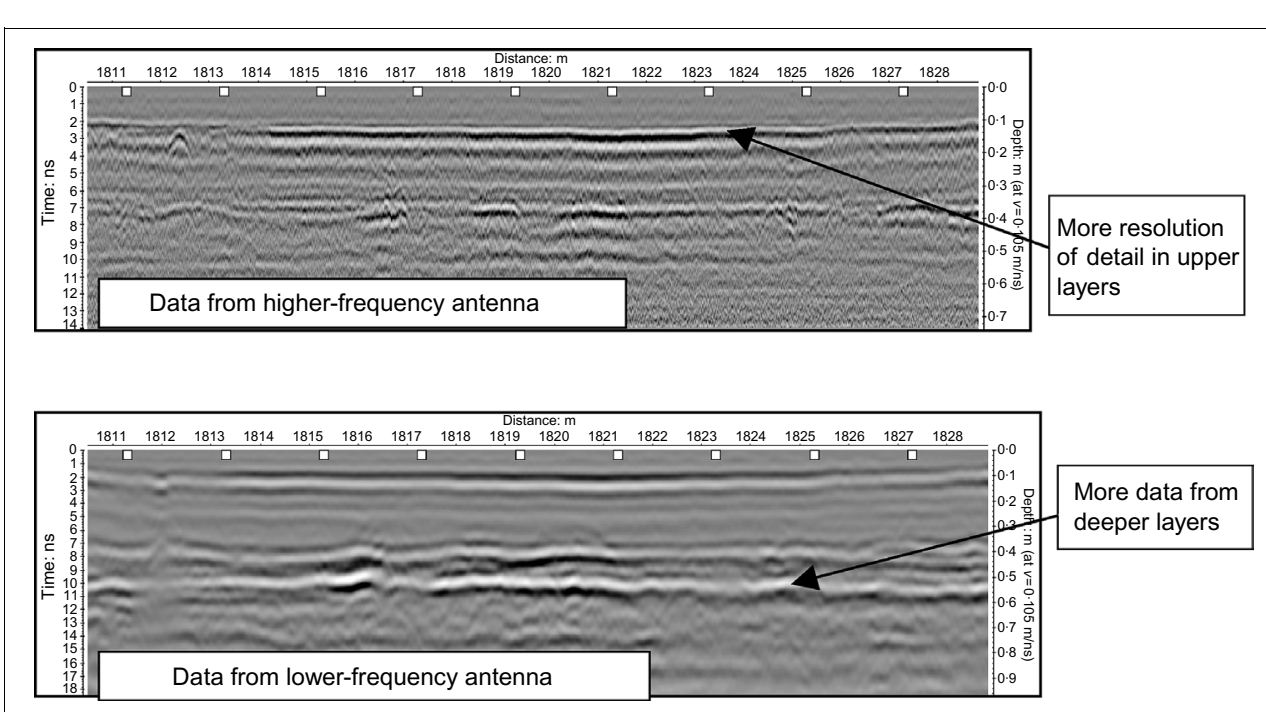

Fig. 2. Contrast in resolution and depth of signal penetration for two different frequency antennae along the same section of road
GPR hardware and software, occurred mainly since the 1990s. The development of greater processing power, smaller component size, user-friendly software and the ability to perform vehicle-towed surveys have contributed to the increased use of GPR on trunk roads and its inclusion in the UK Design Manual for Roads and Bridges (DMRB). ${ }^{5}$ However, GPR perhaps remains underutilised and its potential is not fully realised in many engineering and geological applications, such as in urban road investigations where conditions are variable.

Despite these recent developments, there are several issues that must be considered when planning the use of GPR. Certain pavement and soil conditions can affect the quality of GPR data; examples include high material water contents, high material conductivity and pavement reinforcement that masks deeper features. However, when such conditions are expected and recognised in surveys, GPR can still provide an accurate and applicable tool for urban pavement investigations. ${ }^{6}$

\subsection{Limitations of GPR}

The quality of GPR data obtained from a survey is a function of several factors, including material properties and conditions, and the actual GPR system used (antennae type, power, signal gain settings used and survey methodology). The amount of information obtained is affected by the processing and analysis procedure used (software, procedures performed, data presentation, etc., see Fig. 3). Furthermore, the skill of the GPR operator and data analyst can also affect the results obtained. Many of these factors can be addressed to optimise data and information quality; some, however, are less controllable. Generally, in-service materials have a range of values of dielectric constant, so a (dielectric) contrast between different materials will not always be apparent, and the resulting low reflection coefficient may mean that resolution of material boundaries is difficult. Also, wet materials tend to absorb and attenuate GPR signals, meaning less energy is reflected, resulting in greater difficulty in resolving layers from GPR data. Disintegrated material boundaries can also prove difficult to map accurately on pseudo-sections. These factors can cause uncertainty in the identification of distinct boundaries between materials. There will always be some situations where site properties mean that, even if every other aspect of the investigation is conducted to the highest standard, GPR data cannot adequately identify relevant features.

\section{URBAN ROADS}

A large range of road types exists in UK urban areas, from low-volume local estate roads to major access roads and urban motorways. Many urban roads have 'evolved' and may have been subject to periodic overlaying or reconstruction as traffic and the loading imposed have increased over many years or even centuries. It is not uncommon for roads in 


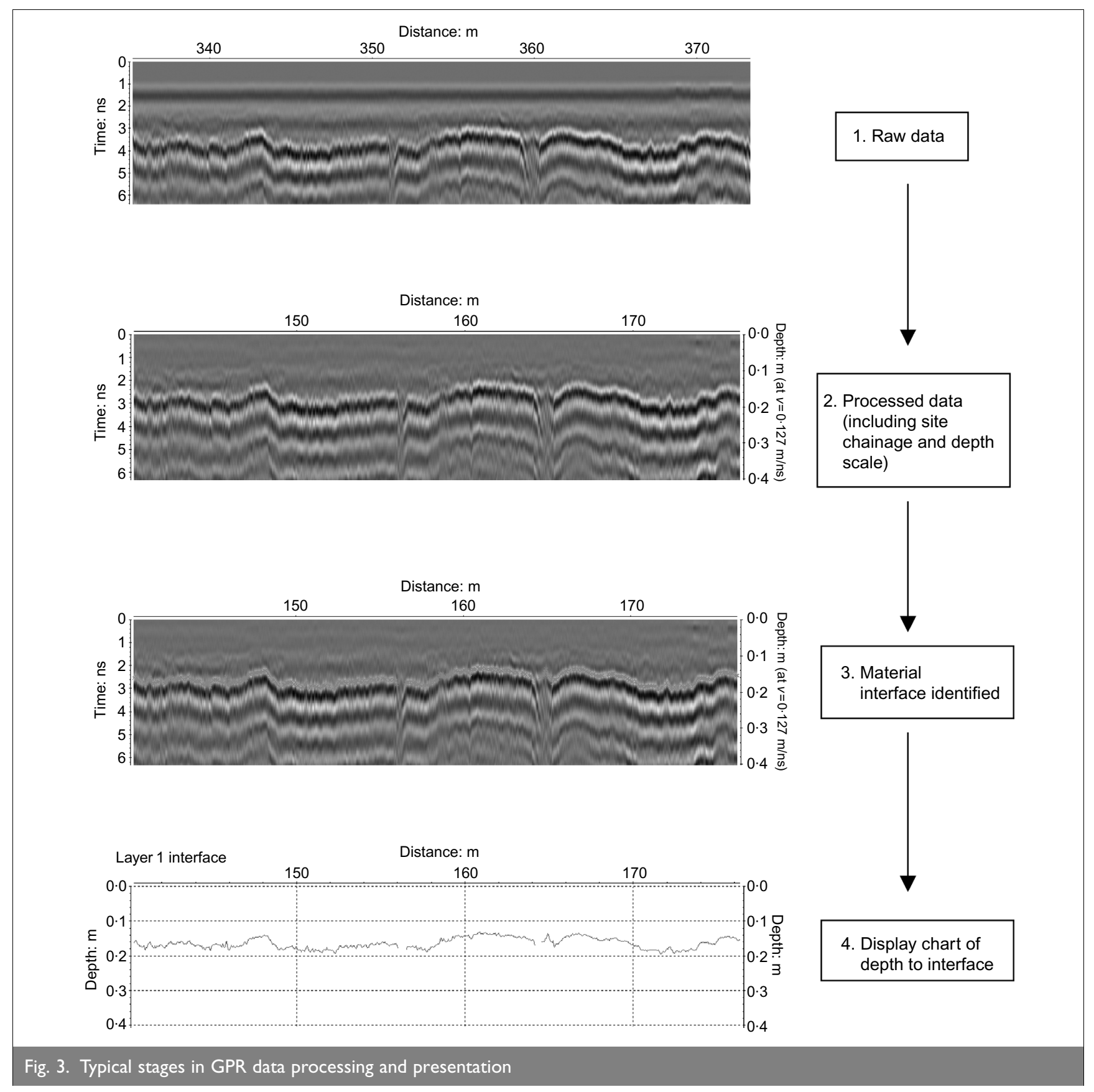

long-established towns and cities to have developed from a track into a paved road and finally into a 'modern' layout. Such roads frequently have highly variable non-standard construction, particularly in the lower layers where new materials may have been placed over the original structure. In such situations, the ability to undertake efficient site investigations of the pavement structure to determine the thickness, variability and nature of the materials is particularly important in order to target remedial measures and construction methodologies.

\section{I. Use of GPR on urban roads}

The main use of GPR proposed in the DMRB ${ }^{5}$ is to establish layer thickness for integration with falling weight deflectometer (FWD) data to allow a detailed stiffness assessment of pavement layers. Other uses include the detection of construction changes and the location of voids and wet patches (indicating poor support), reinforcing bars and excess sub-base moisture (indicating poor drainage). These factors all relate to the reflection of energy caused by changes in the materials within the pavement structure.

In the 1990s the use of GPR to provide 'network-level' surveys was established. More recent work integrates the routine use of GPR, FWD data and information from other pavement condition assessments within pavement management systems. ${ }^{7}$ Despite the development of 'routine' GPR investigations, the often variable nature of urban pavements and geology means that using standard GPR investigation methodologies (devised for trunk roads) on urban sites will frequently yield inadequate information.

\subsection{Variability of GPR results}

As mentioned above, in situ materials generally have a range of dielectric constant rather than a specific value. Asphalt pavement materials have been shown to have constants in the range of 3.5-10 (corresponding to radar signal speeds of 
95-160 mm/ns) suggesting that the range of radar propagation speeds for in-service pavements could be large. ${ }^{8}$ When conducting GPR surveys on pavements it is therefore important that actual layer depths are obtained (usually by coring), in order to calibrate the GPR, to ensure accuracy of the data. This becomes especially critical in urban locations where the nature of both the road pavement and the underlying ground tends to be highly variable.

The reported level of accuracy achievable for layer thickness evaluation is variable, and it must be noted that site-specific conditions will play a part in this, as will the GPR data collection parameters used. The guidance in DMRB ${ }^{5}$ states that ' $10 \%$ level of accuracy can generally be achieved for layers greater than $75 \mathrm{~mm}$ thick' and that ' $6 \%$ level of accuracy can be achieved for layers greater than $125 \mathrm{~mm}$ thick'. In the majority of cases GPR is a useful non-invasive tool for the engineer-it provides valuable information and increases understanding of the condition, features and variability of the pavement and ground, leading to longer-term cost and time savings.

\section{CONDITION INVESTIGATION OF URBAN ROADS}

Visual surveys are common for routine inspection of UK urban road condition and are used to target further detailed investigation-often the first indication that maintenance may be required is noted by the appearance of cracking or rutting of the road surface.

The $\mathrm{DMRB}^{5}$ contains guidance on techniques for assessing the condition of trunk roads and these methods are also used for the detailed investigation of urban roads. These investigations are then used to plan maintenance treatments. However, as noted above, the variable nature of many urban roads presents a more variable and challenging assessment environment than that encountered in trunk road or motorway investigations where pavement structures tend to be more consistent and homogeneous. A good overview of the in situ assessment of pavement structural conditions, from a UK perspective, is given by Rockliff. ${ }^{9}$

\section{A GPR INVESTIGATION OF AN URBAN ROAD}

In 2005, information was required on the internal structure of an urban 'evolved' road in the West Midlands. The road was a local high street with both residential and commercial properties nearby. From visual inspections, the surface of the road was showing signs of severe structural damage. The bituminous road pavement was generally in a poor condition and had undergone several maintenance/resurfacing treatments over a number of years, but it was thought the pavement foundations had remained untreated. Ruts and cracks could be observed clearly on both repaired and unrepaired areas; planing off the bituminous layers and replacing them with new material was being considered.

The construction details of the road were known to be nonstandard and variable and, although little detailed information was available, it was thought to be one of a number of similar road structures in the region. Information on the depth of the various layers in the road, especially to the bottom of the bituminous layer along the length of the site and identification of the presence and thickness of sub-base, had to be determined before planing could proceed.
A site investigation was devised with the aim of, first, determining whether GPR could provide adequate information to assist detailed planning of the maintenance work and, second, optimising a GPR methodology to provide a basis for detailed routine investigations on other similarly variable pavements. The GPR site investigation was combined with intrusive evaluation techniques.

A desk study of available pavement data was undertaken and two initial trial pits were excavated to aid the planning of further evaluations. These pits showed the sub-grade to be a silty clay, overlain by a $50 \mathrm{~mm}$ fine ash layer, acting as a bed for stone blocks or cobble stones (known locally as 'pitchings') that formed the original pavement for which there was no foundation as such (Fig. 4). The current bituminous pavement had been constructed over the top of the pitchings. It was originally thought that there was a granular sub-base acting as a regulating layer above the pitchings along the entire road, but initial investigations indicated that the sub-base layer was highly variable, ranging from $80 \mathrm{~mm}$ thick in some places to zero (no sub-base) in others.

\section{I. Site investigation}

The GPR unit used for the investigation comprised three antennae operating at frequencies of $1.5 \mathrm{GHz}, 900 \mathrm{MHz}$ and $400 \mathrm{MHz}$. Thus, for each survey line, three GPR datasets were obtained (one at each frequency) to maximise the information available and accommodate the resolution/depth/frequency relationship of GPR. Using three antennae had no operational effect on the investigations, as a purpose-built antennae housing was towed behind the survey vehicle (Figs 5 and 6). The antennae were linked to a data collection unit inside the vehicle, displaying real-time raw data (pseudo-section) profiles of the radar travel time. The raw data gave an initial indication of the layers and interfaces on site; however, further post-survey data analysis was required.

A survey wheel was connected to the antennae and the rate of radar pulses (scans) transmitted (i.e. the number of pulses per second) was driven by the movement of the wheel. When connected to a survey wheel, different GPR systems have

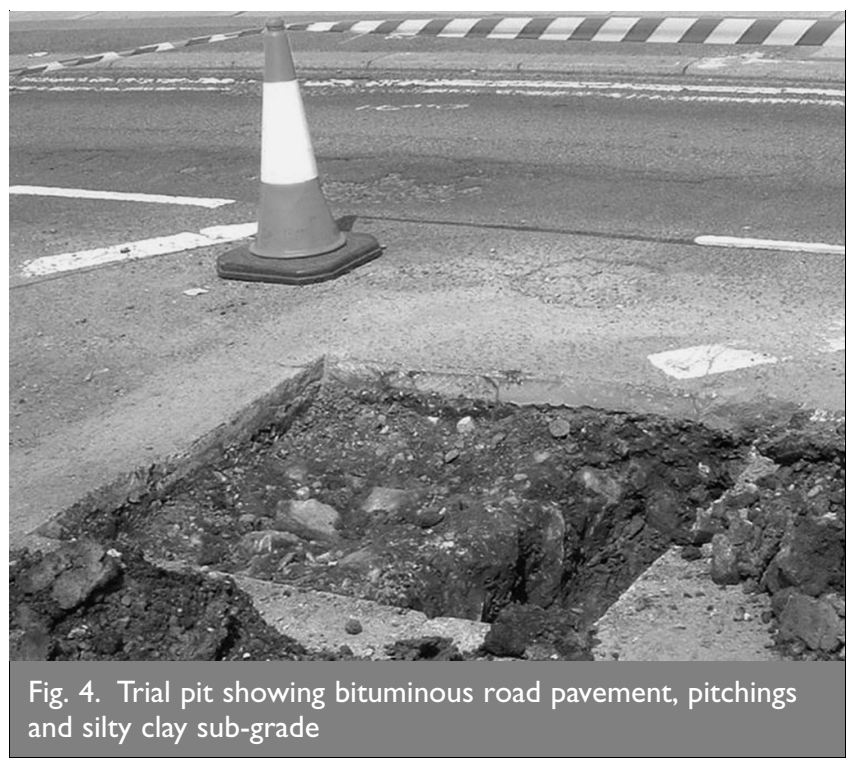



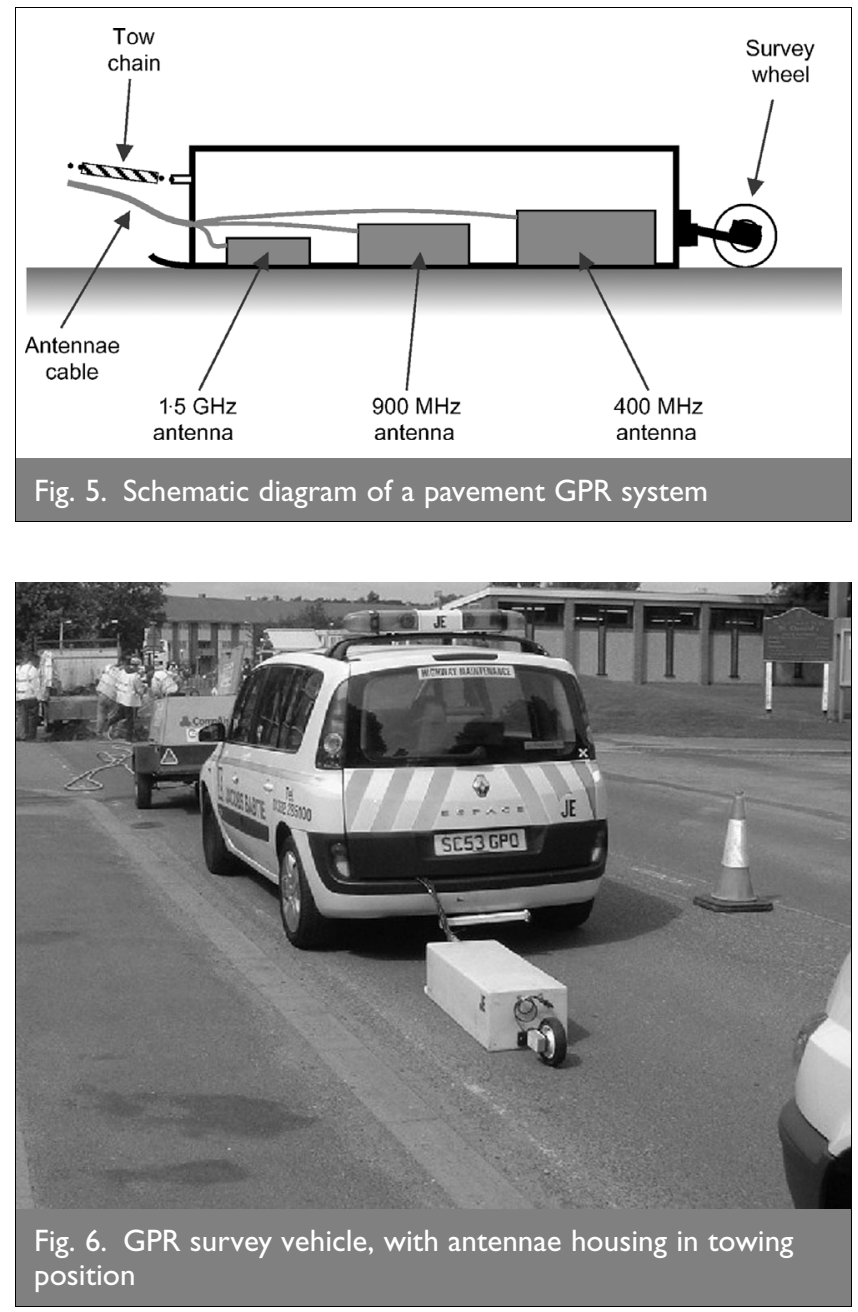

different maximum scan rates; this, along with the speed at which the antennae move along the ground, determines the scan spacing (i.e. data points over a given distance). GPR network-level surveys can be conducted at high speeds ( $40 \mathrm{~km} / \mathrm{h}$ or more). However, the faster the speed the less scans per metre. As network survey roads tend to be relatively homogeneous in construction, radar scans every $0.5 \mathrm{~m}$ along a survey line is an acceptable and not uncommon rate. Slower surveys speeds will increase the survey time, but for variable urban sites a more detailed picture of construction and material features is required. A relatively high-speed survey may miss details or features of interest. The GPR system parameters were set so that a scan was taken approximately every $0.04 \mathrm{~m}$ along each survey line, requiring a vehicle speed of approximately $3 \mathrm{~km} / \mathrm{h}$.

It is common practice to collect GPR data in only one wheel-path per lane. After consideration of the existing information indicating the variable nature of the pavement at the site and the cracking and ruts present on the road, it was felt that surveys in one wheel-path would miss important features of the pavement structure. GPR survey runs were thus taken in both the near-side and off-side wheel-paths in each lane, and a number of transverse runs were also taken (pushed by hand within the confines of site traffic management, see Fig. 7). This approach, although more time-consuming, meant that a comprehensive picture of the road structure could be collected and pavement features and properties could be observed that would have been missed if a 'standard' survey had been used.

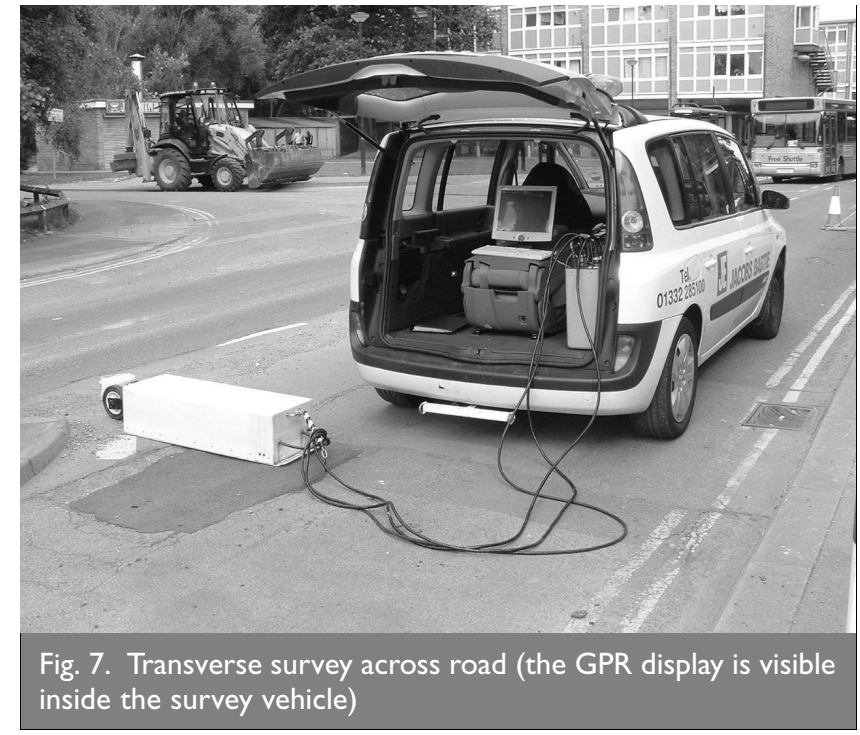

GPR data were referenced to local site chainages, which were marked from fixed features that could be easily located on subsequent site visits (such as centre lines of road junctions). The importance of accurate site chainages is often overlooked, but is particularly important where features occur and data are collected at relatively close spacing. The positions of previously taken invasive samples were recorded directly onto the GPR raw data as the antennae passed the locations. New core locations undertaken concurrently during the work (targeted by the GPR team from the raw data to optimise their value) were also plotted.

A post-survey analysis (in conjunction with consideration of other site data) was undertaken to yield a more comprehensive and accurate determination of layer and feature depths, an indication of material type and integrity, and identification of homogeneous and anomalous lengths of pavement

construction. Core information was used to recalibrate the GPR data by correlating the material depths from the cores to radar travel times from GPR signals at the exact core locations. Radar signal speed through the material could then be calculated and used to determine depths within the road structure for the lengths of the GPR survey between core locations, thereby giving the most accurate calibration of the GPR data. In total, 13 cores (old and new) were taken and approximately $2000 \mathrm{~m}$ of GPR survey lines were obtained. The rate of cores per GPR survey length is high compared with many investigations, but the trial nature of the work and the existence of previous core data facilitated this. Obviously the number of cores required for adequate calibration of data for a given survey depends on the homogeneity of the site materials encountered, and will vary from site to site.

The data were processed and filtered to include corrections for the fact that the GPR antennae were not flush with the road surface, background noise removal and conversion of signal travel times to pavement depth. During the site investigation the methodology employed was reviewed and revised with the aim of optimising the GPR survey procedure and information obtained.

\subsection{Findings from the survey}

The GPR data identified that there were actually three distinct longitudinal pavement sections rather than one as originally 


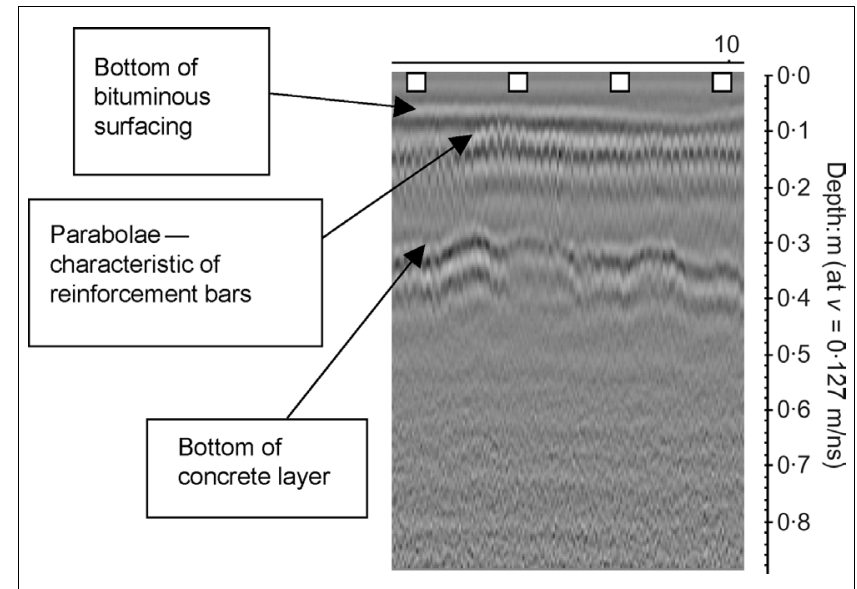

Fig. 8. GPR profile of thin bituminous surface over reinforced concrete slab

thought. These consisted of a short section of surfaced reinforced concrete pavement (300 $\mathrm{mm}$ thick, Fig. 8), a section of poor-condition bituminous pavement (150 mm thick) and a section of sounder slightly thicker bituminous pavement (180 mm). The thickness changes were easily identifiable and the condition of the material was assessed based on correlations with the intrusive investigations. Much of the pavement appeared to be in poor condition, with areas of sound and partially deteriorated pavement materials overlying areas of badly disintegrated material, sub-base and/or pitchings (Fig. 9). The nature of these disintegrated materials meant that identifying discrete GPR layer boundaries in places was difficult because of the mix of materials present, although the presence of these areas could be established. The inability to determine precise layer thicknesses was not just limited to the GPR data-there was also uncertainty in reporting layer thickness from intrusive investigations in these areas. The GPR data showed several areas of the road to contain wet material, and this was confirmed by further trial pits. This meant that the amount of radar energy penetrating deeper in the road structure was reduced, leading to difficulty in identifying the exact top of the pitchings in some areas.

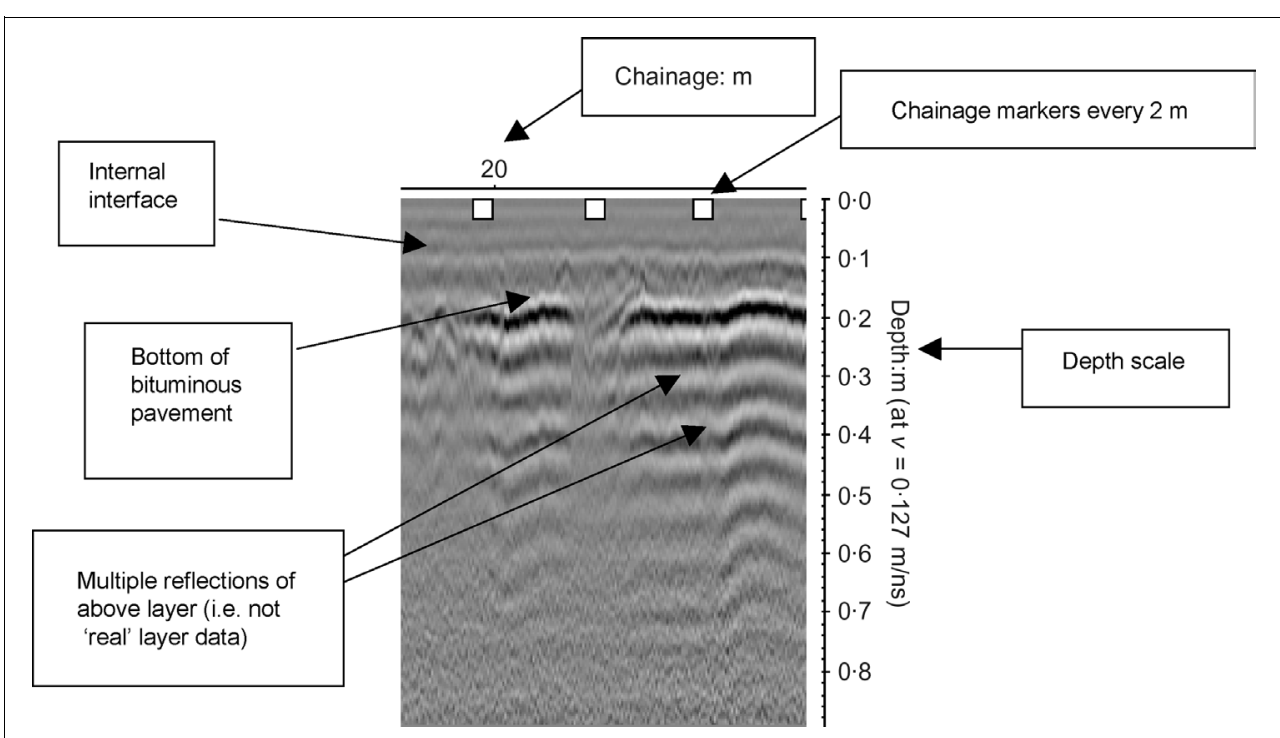

Fig. 9. GPR profile of bituminous pavement over hand pitchings (note loss of resolution in pitchings layer)
Data from transverse GPR surveys proved very useful since material thickness in the upper bituminous pavement tended to be greater in the wheel-paths than in the lane centre (possibly because of previous overlaying of rutted pavement). Without the transverse surveys, this information would not have been discovered. Differences of up to $50 \mathrm{~mm}$ in pavement depths below the road surface to the top of pitchings were discovered, with some sharp variations over short distances. Considering the intended maintenance treatment of planing away existing material, these thickness differences and variations between lane centre and wheelpath were important discoveries. The indication from intrusive investigations that the sub-base layer present in the road was not constant throughout the entire site was confirmed by the GPR data and consolidated throughout the survey area.

From the survey, it could be determined that an attempt to plane material to the depth of the pitching would be difficult, and planing to the base of the bituminous layers (identified by the GPR data) would be more appropriate. Due to the transverse variation in pavement depth, planing of material in three distinct runs per lane was proposed.

\section{DISCUSSION AND RECOMMENDATIONS}

\section{I. Discussion of findings from site investigation}

The investigation was successful in identifying a 'safe' planing depth to which material could be removed. Identification of the bottom of the bituminous pavement was successful, but identification of lower layers (sub-base and top of pitchings) could only be indicated. It is likely that at other similar sites with deteriorated and variable thin materials in poor condition, the confidence in reporting individual layers could also be variable.

Several factors affecting the level of information obtained from this investigation existed during each stage of the process (planning, investigation, processing and reporting). Technical and scientific issues relating to the materials and nature of the site and to the GPR technology used were not necessarily the most influential factors. The physical laws governing radar wave propagation mean that a change in GPR equipment would be unlikely to alter the information obtained. The trial nature of the site allowed the flexibility for the on-site data collection methodology to be adapted to site-specific situations. It is unlikely that changes to the processing procedure would alter the level of information obtained. A key issue to obtaining the best results in such challenging pavement scenarios is for the data provided by each member of the investigation team to be integrated in an optimum way. A close working relationship for the team is therefore essential for the investigation to be of maximum benefit. Concurrent discussions and feedback of information from the various teams involved 
(including coring and GPR crews, laboratory staff, engineering geophysicists, pavement engineers and the client) are essential for the acquisition of optimum information. Ultimately the end user has to receive information in a form that will prove most useful for the purpose for which it is required (e.g. the planning and selection of maintenance).

\subsection{Recommendations for urban road GPR investigations}

In urban sites it is essential that sufficient information is obtained to allow a full assessment of the condition of the pavement in order to plan the most appropriate maintenance treatment. If high-speed GPR methodologies (often used for trunk roads) are employed, information can easily be missed. Time spent on the in situ investigation can lead to much larger time savings by the provision of sufficient information to allow the most appropriate treatment works to be conducted. Clearly, judgement is required on the benefits of certain aspects of the GPR methodology, such as taking multiple survey lines and transverse survey lines, which add time but increase the amount of information provided; these factors will be site-specific. However, time and money saved in the evaluation stage by performing a less than adequate investigation may result in much greater costs during the maintenance stage due to inappropriate construction techniques being selected, maintenance requirements not being fully assessed, or treatments not addressing the full nature of the problem.

When conducting GPR investigations of urban sites, as much information as possible should be obtained about the site before any investigation is planned. Information on the nature of the site-age of the road, 'modern' or evolved construction, variable materials or homogeneous construction, sub-grade information, etc.-will affect the methodology used for the in situ investigation.

Where urban roads are thought to be of highly variable nature, or there is little information available, it is recommended that the following points are considered.

(a) Several antennae, providing a range of radar frequencies, should be used to provide the best coverage of depth of penetration and resolution.

(b) The use of low-speed surveys (i.e. giving a high number of radar pulses per distance travelled) is recommended for sites with highly variable construction so that relevant features in the road structure are not missed.

(c) Along with longitudinal survey profiles in both wheelpaths, transverse surveys across the road are recommended.

(d) Intrusive surveys (usually in the form of cores, but also trial pits) are necessary to calibrate GPR data to a suitable level of accuracy. The number of intrusive investigations will depend on the nature of the site.

(e) Special attention should be paid to a sensible and easy-tofollow site chainage system, marked from fixed locations on site. (f) All core locations should be marked directly on the GPR pseudo-section to provide an accurate correlation of core locations with GPR survey data.

(g) Additional cores should be identified and excavated during the same work period as the GPR survey.

(h) Discussions should be ongoing between the different members of the investigation team (coring crew, GPR survey team, engineers, project managers, client, etc.) to provide a coordinated approach to the investigation.

(i) Team members, especially the end users of the information, should be made aware of the various uses and limitations of GPR data.

\section{ACKNOWLEDGEMENTS}

The authors acknowledge contributions by J. Nash, D. Rieley and A. Simms. We are grateful to M. Preston for assistance in organising the site work. The site investigation work described in this paper was funded by Coventry City Council. The study by the authors into the use of GPR receives contributory funding from the EPSRC via the Engineering Doctorate Scheme run from the Centre for Innovative and Collaborative Engineering at Loughborough University.

\section{REFERENCES}

1. Mooney M. A., Miller G. A., Teh S. Y. and Bong W. Importance of invasive measures in assessment of existing pavements. Journal of Performance of Constructed Facilities, 2000, 14, No. 4, 149-154.

2. Matrhews S. L. Subsurface Radar as an Investigative Technique. Building Research Establishment, Watford, 1998, Report BR 340.

3. Olnoеfт G. R. Maximizing the information return from ground penetrating radar. Journal of Applied Geophysics, 2000, 43, Nos. 2-4, 175-187.

4. Daniels D. J. Ground Penetrating Radar, 2nd edn. Institution of Electrical Engineers, London, 2004.

5. Highways Agency. Design Manual for Roads and Bridges, Volume 7: Pavement Design and Maintenance. The Stationery Office, London, 2006.

6. BARNES C. L. and TRotTIER J.-F. Phenomena and conditions in bridge decks that confound ground-penetrating radar data analysis. Transportation Research Record, 2002, No. 1795, 57-61.

7. Noureldin A. S., Zhu K., Shuo L. and HarRis D. Network pavement evaluation with falling weight deflectometer and ground penetrating radar. Transportation Research Record, 2003, 1860, 90-99.

8. Davis J. L., Rossiter J. R., Mesher D. E. and Dawley C. B. Quantitative measurement of pavement structures using radar. Proceedings of the 5th International Conference on Ground Penetrating Radar, Kitchener, 1994, 319-334.

9. RockLIFF D. Design and maintenance of asphalt pavements. In Asphalts in Road Construction (HUNTER R. N. (ed.)). Thomas Telford, London, 2000.

\section{What do you think?}

To comment on this paper, please email up to 500 words to the editor at journals@ice.org.uk

Proceedings journals rely entirely on contributions sent in by civil engineers and related professionals, academics and students. Papers should be 2000-5000 words long, with adequate illustrations and references. Please visit www.thomastelford.com/journals for author guidelines and further details. 